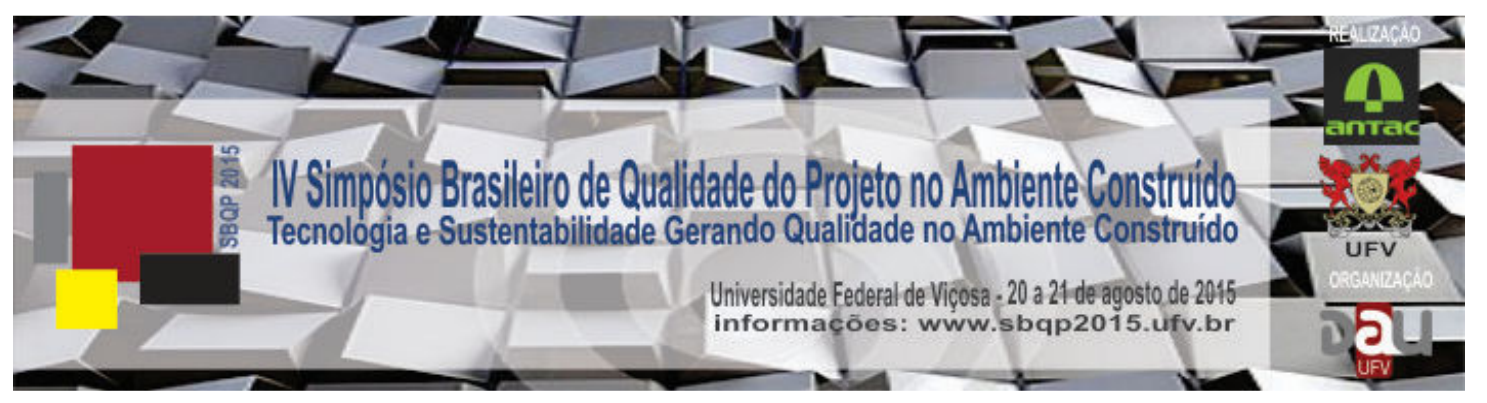

\title{
PROGRAMANDO ESPAÇOS DE APRENDIZAGEM: UMA CONTRIBUIÇÃO PARA A EDUCAÇÃO BRASILEIRA ${ }^{1}$
}

\author{
ALVARES, Sandra Leonora \\ Universidade Estadual de Campinas, alvares.sandra@hotmail.com \\ KOWALTOWSKI, Doris C.C.K. \\ Universidade Estadual de Campinas, doris@fec.unicamp.br
}

\begin{abstract}
RESUMO
Este artigo foca no processo de projeto de edifícios escolares com o intuito de criar ambientes de aprendizagem de qualidade para o ensino fundamental brasileiro. Para tanto, requisitos de projeto estão sendo organizados para dar suporte a fase de Programa Arquitetônico do processo de projeto de edifícios escolares. Assim, este estudo tem como objetivo identificar e organizar requisitos de projeto que norteiem a construção de edifícios escolares relacionando comportamento humano e ambiente construído, bem como teorias pedagógicas. Para tanto, um banco de dados está sendo criado para facilitar o acesso a informações relevantes para o desenvolvimento do projeto arquitetônico de escolas. Uma pesquisa bibliográfica foi conduzida para identificar dados sobre ambiente de aprendizagem, arquitetura escolar, psicologia ambiental, métodos pedagógicos e leis que orientam a educação brasileira. A ferramenta para apoiar a fase do Programa Arquitetônico, o Problem Seeking, está sendo utilizada para filtrar as informações. No banco de dados as informações são apresentadas através de textos, desenhos, ilustrações e diagramas. Todo item é referenciado para futuros estudos e questionamentos. $O$ banco de dados está sendo implementado no programa ACCESS da Microsoft, específico para banco de dados. A validação do mesmo ocorrerá através de testes com arquitetos e educadores. Por fim, - Banco de Dados deverá aprimorar a qualidade arquitetônica de novas escolas, colaborando para a melhoria da educação como um todo.
\end{abstract}

Palavras-chave: arquitetura escolar, programa arquitetônico, ensino fundamental.

\begin{abstract}
This article focuses on the design process of school buildings, with a goal of creating better quality learning environments for Brazilian primary and secondary education. Design requirements were organized to support the architectural programming phase of the design process of school buildings. The main goal of the study is to identify and to organize design requirements that guide the designing of learning environments, by relating the learning environment as it was built to both human behavior and pedagogical activities. To accomplish this task, a database was created to facilitate the access to relevant information regarding the design of learning environments. A
\end{abstract}

1 Trabalho apresentado no IV SBQP 2015. Universidade Federal de Viçosa.

Disponível em: doi> http://dx.doi.org/10.18540/2176-4549.6057 
literature research was conducted to identify data on: learning environments, school architecture, environmental behavior, teaching and pedagogical methodologies and laws concerning the Brazilian education. The Problem Seeking tool to support the architectural programming phase was chosen for the organization of information. In the database each information is presented as a text with drawings, diagrams and other illustrations. Every item is referenced for further studies. The database will be implemented as a computer application, using ACCESS by Microsoft, a specific software to create database. Validation will occur through testing with architects and educators. Ultimately, the tool should stimulate an architectural quality for new school buildings that can then improve education as a whole.

Keywords: School architecture, architectural programming, Brazilian primary and secondary education.

\section{INTRODUÇÃO}

A educação no Brasil é motivo de muitas discussões que questionam a sua qualidade e visam o seu aprimoramento. Essa preocupação é resultado de um longo passado de omissões com relação à educação básica dos cidadãos brasileiros. Tal fato, impõe ao país esforços redobrados direcionados à implementação de melhorias na educação (CUNHA, 2013). Para aprimorar a qualidade do ensino brasileiro o Estado precisa investir não só na formação do professor, mas também no espaço físico que acolhe as práticas pedagógicas (FRANÇA, 2014).

No que diz respeito ao ambiente físico, pesquisas comprovam que o edifício escolar pode influenciar tanto positivamente como negativamente no desempenho dos alunos. Essas pesquisas abrangem os diferentes aspectos que compõem o edifício escolar, abordando essa complexa construção sob diferentes enfoques: avaliação pós-ocupação voltadas para o conforto ambiental (AZEVEDO, 2012; SANOFF, 2001; ORNSTEIN \& ONO, 2010, BARRET ef al., 2012, MACHADO et al., 2008) e para análises do comportamento humano no ambiente construído (ELALI, 2008), como também estudos direcionados para seu caráter histórico e simbólico (BUFFA \& PINTO 2002) e a relação entre ambiente de aprendizagem e pedagogia (TAYLOR, 2009; SANOFF, 2001; KOWALTOWSKI, 2011; AZEVEDO, 2002, NAIR et al, 2009).

Entre os enfoques que a pesquisa sobre o espaço escolar pode assumir, este artigo destaca a propriedade que o edifício escolar tem de expressar e refletir, para além de sua materialidade, determinados discursos, podendo ser considerado uma forma silenciosa de ensino ou um currículo invisível (ESCOLANO, 2001). Foca-se, portanto, na discussão sobre a importância de se estabelecer uma conexão entre o projeto do espaço escolar e a proposta pedagógica da instituição, interesse de pesquisadores como Taylor, (2009); Sanoff, (2001); Kowaltowski, (201 1), Lippman, (2011), Azevedo (2002).

No cenário da educação brasileira, é necessário que projetistas e pedagogos conheçam a importância de se estabelecer uma conexão entre ambiente de aprendizagem e proposta pedagógica, uma vez que, a Lei de Diretrizes e Bases da Educação Nacional de 1996 garante às escolas brasileiras a liberdade de ideias e concepções pedagógicas. Esta autonomia concedida às instituições de ensino também traz consigo a necessidade de adequação do espaço escolar as suas atividades pedagógicas, pois o ambiente de sala de aula é a expressão direta da filosofia educacional e pode ter parte ativa no processo de ensino e aprendizagem (MARTIN, 2002). 
Com a intenção de contribuir para o processo de projeto do edifício escolar que dê origem a espaços de aprendizagem de qualidade esta pesquisa está empenhada em construir um Banco de Dados com informações relevantes que auxilie o arquiteto na concepção de espaços escolares coerente com a proposta pedagógica da instituição escolar e que estimule os alunos em seu aprendizado. Com acesso a informações que relacionam métodos pedagógicos ao ambiente de aprendizagem e ao comportamento humano, - projetista terá a possibilidade de conceber espaços escolares mais adequados às atividades pedagógicas e que encoraje o estudante em seu aprendizado.

Dessa forma, esta pesquisa tem como objetivo geral identificar e organizar requisitos de projeto que norteiem a construção de espaços de aprendizagem para crianças do ensino fundamental, relacionando comportamento humano e ambiente construído, bem como teorias pedagógicas. Com a ferramenta de apoio ao processo de projeto do edifício escolar, o Banco de Dados, busca-se melhorar a qualidade dos espaços físicos escolares do ensino fundamental brasileiro, afim de que possa ser considerado como o terceiro professor.

\section{AMBIENTE DE APRENDIZAGEM VERSUS PROPOSTA PEDAGÓGICA}

A relação entre ambiente de aprendizagem e método pedagógico tem sua importância revelada em estudos de pesquisadores como Sanoff (2001) que afirma que a organização do ambiente de aprendizagem deve refletir a proposta educacional que o professor tem em mente; Fisher (2005) que relata que atividades pedagógicas requerem espaços com qualidades específicas a fim de que o ensino seja efetivo e Azevedo (2002) que defende que arquitetos devem conceber os espaços escolares a partir das premissas pedagógicas, do conhecimento das necessidades dos usuários e seu imaginário coletivo. Assim, é importante que o arquiteto conheça as questões relacionadas à abordagem pedagógica, pois ao definir os espaços e usos da instituição escolar, pode influenciar a definição do conceito da escola (KOWALTOWSKI, 2011).

No entanto, a forma do espaço, arranjos de layout e signos do espaço físico expõem alunos e professores a estímulos. Estes podem incentivar o movimento, chamar a atenção para determinados lugares, encorajar o envolvimento na atividade ou não (SANOFF, 2001). Assim, é importante também considerar as contribuições da Psicologia Ambiental para o projeto do edifício escolar, pois - meio físico atuando de modo não verbal provoca impacto direto e simbólico sobre seus usuários, facilitando ou intimidando comportamentos (ELALI, 2003). Por exemplo, alguns arranjos de layout incentivam as interações sociais, enquanto outros inibem. Nos arranjos de layout chamados sociofugal, - olhar direto é protegido ou até cancelado. Essa situação é vivida em uma sala de aula onde os alunos estão organizados em linhas e colunas, com o contato visual entre os estudantes dificultado, já que veem somente as costas um dos outros. Nos arranjos de layout denominados de sociopetal o olhar é maximizado, pois se considera o olhar direto um fator importante e necessário para manter a participação e o engajamento do indivíduo na situação em que está vivendo. O layout característico do arranjo sociopetal é o radial, utilizado no ambiente escolar em debates e seminários (SCOTT-WEBBER, 2009). 
Dentro desse contexto, atualmente, busca-se o ambiente de aprendizagem como o terceiro professor que é um conceito característico da escola do século XXI, onde o ambiente de aprendizagem passa a ser reconhecido como um elemento de mediação no processo de aprendizagem (LIPPMAN, 2010). Vários pesquisadores o definem de diferentes maneiras. Para Kowaltowski, (2011) o ambiente de aprendizagem que "trabalha como o terceiro professor" é capaz de suportar as atividades pedagógicas e estimular o aprendizado do aluno. Sanoff (2001) afirma que o ambiente de aprendizagem pode ser considerado como um professor desde que o espaço tenha o poder de organizar e promover relações prazerosas entre pessoas de diferentes idades, de promover mudanças e proporcionar um aprendizado efetivo. Taylor (2009) defende que a arquitetura pode ensinar se os elementos do espaço realçarem os conceitos que serão apreendidos nas disciplinas, transformando o ambiente em um currículo invisível.

Portanto, considera-se que o ambiente de aprendizagem não pode ser visto somente como pano de fundo das atividades pedagógicas, mas um elemento mediador que pode contribuir tanto positivamente como negativamente no processo de ensino (CLEVELAND, 2011).

\section{A EDUCAÇÃO NO BRASIL}

A educação brasileira é regida por diversos documentos, entre eles a Constituição de 1988, o Estatuto da criança e do adolescente de 1990, a Lei de Diretrizes e Bases da Educação Nacional 1996 (LDB), Diretrizes Curriculares Nacionais da Educação Básica de 2013 e os Parâmetros Curriculares Nacionais de 1997. Estes instrumentos legais torna a educação no Brasil um direito da criança e do adolescente, bem como um dever do Estado. Reconhecem, também, o princípio da gestão democrática, a composição de um corpo docente através de concurso público, a exigência de elaboração do projeto político-pedagógico de cada escola e determina uma forte vinculação da escola com a respectiva comunidade (SAVIANI, 2008).

Entre todos os instrumentos acima relatados, os Parâmetros Curriculares Nacionais (PCNs) trazem orientações pedagógicas e conteúdos a serem abordados em sala de aula. Esse documento expressa, também, direcionamentos da prática educativa que tem como eixo a formação de um cidadão autônomo e participativo, a partir de um ensino centrado no aluno (BRASIL, 1997). Dessa maneira:

- O aluno deve ser o sujeito de seu processo de aprendizagem.

- O professor tem o papel de mediador na interação dos alunos com os objetos de conhecimento, bem como na interação dos alunos entre si.

A liberdade das ideias e concepções pedagógicas prevista na Lei de Diretrizes e Bases da Educação Nacional de 1996, já se faz presente nas escolas públicas brasileiras. Existem iniciativas que vem se destacando pelos resultados do desempenho de alunos. Exemplos de escolas públicas com práticas pedagógicas centradas no aluno e com o professor como facilitador são: 


\section{- Escola Amorim Lima.}

Escola Municipal de Ensino Fundamental Desembargador Amorim Lima é uma Instituição Pública que diariamente recebe 800 alunos, do $1^{\circ}$ ao $9^{\circ}$ ano, nos períodos da manhã e da tarde. O eixo central de sua pedagogia é a valorização da autonomia do aluno e seus princípios são fundamentados na gestão participativa, com processos decisórios que incluem estudantes, educadores e funcionários. A relação entre aluno e educador funciona da seguinte maneira:

- Cada aluno tem um educador tutor que é responsável pela avaliação do progresso de aprendizagem do estudante.

- Um professor, geralmente, é responsável por 20 alunos por período.

- Tutor e aluno se encontram, geralmente, uma vez por semana, embora o aluno pode procurar o tutor sempre que precisar.

Dentro dessa proposta democrática de ensino, os blocos de sala de aula e as grades nas janelas e portas não correspondiam à nova realidade da escola. Tal situação exigiu que se reformasse o espaço físico escolar. Assim, as paredes de dois grandes blocos de salas de aula foram derrubadas, dando origem a dois grandes salões. Nestes os alunos sentam em grupos de quatro para realizarem as suas atividades pedagógicas. As antigas paredes de cor cinza foram pintadas de cores variadas ou revestidas com azulejos pintados (GRAVITÁ et al., 2013), (http://amorimlima.org.br/).

\section{- Projeto Gente:}

Criado na cidade do Rio de Janeiro, este projeto foca suas atividades no ensino centrado no aluno e do uso de novas tecnologias. Essa proposta educacional busca personalizar o processo de aprendizagem, adequando-o as necessidades do aluno e tornando-o protagonista do seu processo de ensino através apropriação de novas tecnologias. A intenção é formar cidadãos autônomos, solidários e competentes, bem como desenvolver no aluno a aptidão de viver em um mundo em constante transformação. Ou seja, espera-se que o aluno seja capaz de buscar, analisar e avaliar informações e fontes; solucionar problemas e tomar decisões, bem como utilizar de forma criativa as ferramentas de produtividade.

A primeira escola a se adequar ao projeto GENTE foi a Escola Municipal André Urani, na Rocinha, com capacidade para atender 180 alunos do $7^{\circ}$ ao $9^{\circ}$ ano. A proposta se organiza da seguinte maneira:

- A educação é integral com o aluno permanecendo na escola em torno de sete a oito horas.

- Não existem turmas, anos ou salas de aula.

- Avaliações são aplicadas através de máquina de testes, com correção automática.

- Tablets e smartphones integram o material escolar dos alunos e docentes.

O espaço de aprendizagem destinado a essa proposta teve que ser reformulado para receber as alterações no processo de ensino e aprendizagem. Foram criados espaços amplos e abertos, para possibilitar o trabalho coletivo de alunos e professores, transformando o ambiente em local atrativo ao aprendizado, com identidade visual e mobiliário próprio. As alterações também visaram à acomodação dos equipamentos de tecnologia utilizados no ensino. (http://gente.rioeduca.net/) 
Em ambos os exemplos, observou-se que foram necessárias alterações no espaço físico, pois as novas concepções de ensino não se encaixaram nas antigas estruturas. Destaca-se, assim, a necessidade de o projetista conhecer informações relacionadas tanto as concepções pedagógicas como da psicologia ambiental. Estas informações orientam o projeto de ambientes escolares mais adequados para abrigar as novas metodologias de ensino e suas atividades pedagógicas.

\section{O PROCESSO DE PROJETO DO EDIFÍCIO ESCOLAR}

O processo de projeto é uma ação que se apresenta em constante negociação entre problemas e soluções, abrangendo diversas fases Programa Arquitetônico, Anteprojeto, Projeto e Execução (LAWSON, 2005). No caso do processo de projeto do edifício escolar, recomenda-se o Processo de Projeto Referencial identificado por Deliberador (2010). Ele se destaca não só por possuir várias fases de avaliação, a de Comissionamento e Avaliação PósOcupação (APO), mas também pela relevância que dá à fase do Programa Arquitetônico.

Para muitos projetistas, o Programa Arquitetônico, primeira fase do processo de projeto, é considerada uma das etapas mais importantes, pois é nesse momento que se estabelece o problema arquitetônico e suas exigências para se chegar à solução projetual (PEÑA e PARSHALL, 2001). Para o projeto do edifício escolar, desde essa primeira etapa, o arquiteto deve buscar, através de seu trabalho, idealizar um ambiente de aprendizagem que "trabalhe" como mediador do aprendiz, do processo de aprendizagem e do que será aprendido. Para incorporar tal qualidade no espaço escolar, é preciso que o projetista domine conhecimentos interdisciplinares, como: as diferentes maneiras pelas quais as pessoas aprendem, como o aluno e o ambiente social influencia o aprendizado, como a pedagogia é usada, como o ambiente pode ser desenhado para promover o engajamento das pessoas nas atividades propostas de maneira que seja cumprido o objetivo (LIPPMAN, 2010). Por ser uma atividade analítica, essa etapa conduz ao levantamento, compreensão e organização de informações necessárias ao desenvolvimento de um edifício novo. A pesquisa por tais dados e/ou informações de diferente natureza deve abarcar fontes distintas: APO, normas, legislações, literatura especializada e os próprios usuários (HORAYAANKURA, 2012; MOREIRA, 2011). Quanto a estrutura do Programa Arquitetônico, Moreira (2011) afirma que deve ser construída de maneira resumida e apresentado através de tabelas e diagramas. A documentação reunida durante os estudos das condições dos propósitos do edifício a ser projetado, também deve acompanhar o Programa Arquitetônico.

Para auxiliar na organização, classificação e interpretação das informações Peña e Parshall (2001) desenvolveram a estrutura conceitual do Problem Seeking que é uma ferramenta de auxílio à elaboração do programa arquitetônico. De acordo com os autores desse instrumento, o objetivo dessa ferramenta é conduzir a etapa do Programa Arquitetônico para uma afirmação do problema de projeto de maneira clara e concisa, ou seja, que não deixe dúvidas (PEÑA e PARSHALL, 2001). Para tanto, o método é estruturado em cinco passos: 
- Objetivos - o que o cliente quer e por quê?

- Fatos - O que se sabe? O que é dado?

- Conceitos - Como o cliente quer atingir as metas?

- Necessidades - Quanto de dinheiro e espaço? Qual a qualidade?

- Problema - quais são as condições significativas que afetam o projeto da edificação? Quais são as direções gerais que o projeto deve tomar?

Estes cinco passos interagem com outras quatro considerações (PEÑA e PARSHALL, 2001):

1. Função - está relacionado às atividades, relações entre os espaços e pessoas;

2. Forma- está relacionada ao local, ao ambiente físico e psicológico, assim como a qualidade do espaço e da construção;

3. Economia - diz respeito ao orçamento, qualidade da construção e custos do ciclo de vida da construção;

4. Tempo - passado, presente, futuro, ou seja, está vinculado às influencias da história, as inevitáveis mudanças a partir do presente e projeções futuras.

Além de oferecer uma estrutura para a organização das informações do Programa Arquitetônico, o Problem Seeking conduz essa etapa do Processo de Projeto através de 143 perguntas. Dessa forma, esse instrumento orienta o processo de programar, a partir de um diagnóstico do contexto e um conjunto de diretrizes que o projeto deverá observar (Kowaltowski, 2011). Portanto, destaca-se a importância da fase do Programa Arquitetônico pois, como afirmam Peña e Parshall (2001), boas construções não acontecem por si somente, mas são planejadas e projetadas para serem funcionais e belas. Esse resultado é alcançado quando clientes e projetistas se juntam num esforço cooperativo.

\section{METODOLOGIA}

Com o objetivo de desenvolver um banco de dados que dê suporte ao processo de projeto escolar, principalmente, na fase do Programa Arquitetônico, a metodologia utilizada por essa pesquisa foi dividida em duas etapas.

\subsection{Pesquisa Bibliográfica}

Para a construção do Banco de Dados uma pesquisa bibliográfica sobre temas específicos foi realizada. Os temas foram:

- Legislação e instrumentos que regem a educação brasileira: foram extraídas as estratégias de ensino mais utilizadas nas disciplinas da formação básica comum.

- Relação entre ambiente de aprendizagem e pedagogia: estão sendo extraídas informações sobre diferentes ambientes de aprendizagem para abrigar distintas atividades pedagógicas. 
- Abordagens pedagógicas: métodos pedagógicos mais conhecidos no Brasil, bem como suas metodologias, metas, objetivos, estratégias de ensino e características dos ambientes de aprendizagem.

- Relação entre comportamento humano e ambiente de aprendizagem: estão sendo identificadas informações relacionadas a conceitos de psicologia ambiental (espaço pessoal, personalização, arranjos sociopetal e sociofugal; affordance) aplicados ao espaço escolar.

Esse levantamento foi armazenado dentro de um banco de dados referencial (ZOTERO). As informações dessas referências foram estruturadas de acordo com o Problem Seeking. Essa organização permite identificar requisitos de projeto para um programa de arquitetura escolar. Para facilitar o acesso às informações levantadas está sendo criado um banco de dados específico para este fim.

\subsection{Construção do Banco de dados.}

O Banco de Dados com informações estruturadas sobre requisitos de arquitetura escolar está sendo implementado no ACCESS da Microsoft, software específico para estruturar bancos de dados. As relações entre as informações estão sendo organizadas de maneira que, após filtradas pelo Problem Seeking, os dados sejam distribuídos em quatro categorias: Abordagens/Pedagogia; Estratégias de Aprendizagem, Ambiente de Aprendizagem, Adequação da Arquitetura versus Pedagogia. As informações da Psicologia Ambiental serão associadas às categorias: Ambiente de Aprendizagem e Adequação da Arquitetura versus Pedagogia (Ver Figura 1). Ressalta-se que todas as informações retiradas da literatura serão referenciadas e, quando possível, proporcionarão o acesso a arquivos ou endereços em sites da internet, facilitando, aos interessados, o acesso à origem da informação.

Três tipos de formulários estão sendo criados no banco de dados: cadastro com exemplos mostrados nas Figuras 2 e 3; consulta; e relatórios. O formulário de cadastro permite futuras inserções de dados. Os formulários de consulta e os relatórios tem a função de facilitar o acesso das informações pelo usuário. O Banco de Dados será disponibilizado para ser utilizado na internet.

Após testes realizados junto à profissionais (arquitetos e pedagogos), serão feitos ajustes no Banco de Dados. Para tanto, será avaliada a compreensão do funcionamento do banco de dados, a clareza da informação do conteúdo e a aplicabilidade na elaboração do Programa Arquitetônico de uma escola.

A construção dessa ferramenta de apoio tem a intenção de orientar a concepção do espaço da escola sem padronizar as soluções projetuais, a fim de que a comunidade escolar e sua vizinhança tenha a possibilidade de imprimir sua identidade cultural nos espaços físicos da instituição.

A figura 1 apresenta a estrutura do Banco de Dados e as interações das informações do conteúdo, bem como a sua operacionalização. As figuras 2 e 3 apresentam dois exemplos da interface do formulário "cadastro" do banco de dados. 


\section{Figura 1 - Estrutura do Banco de Dados}

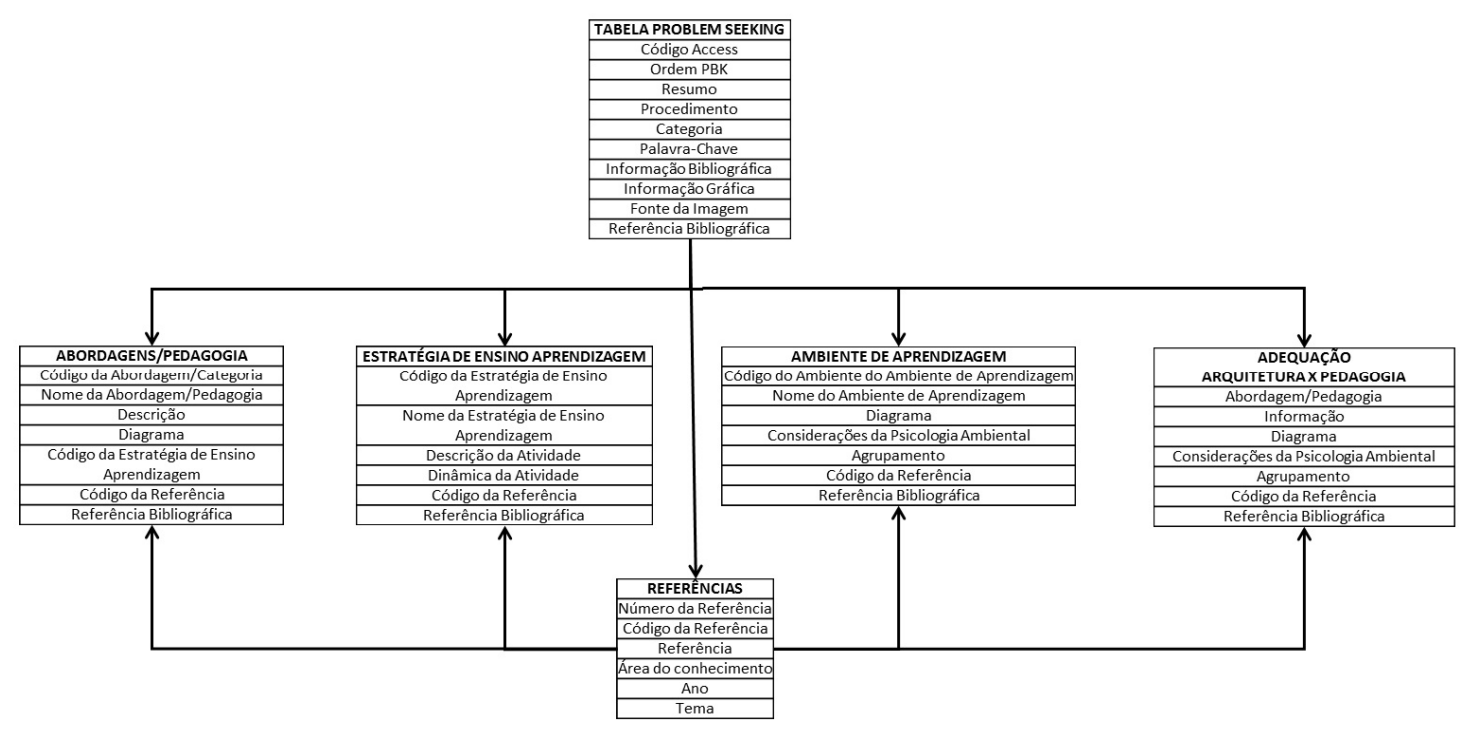

Fonte: Autor

Figura 2 - Formulário de cadastro de dados

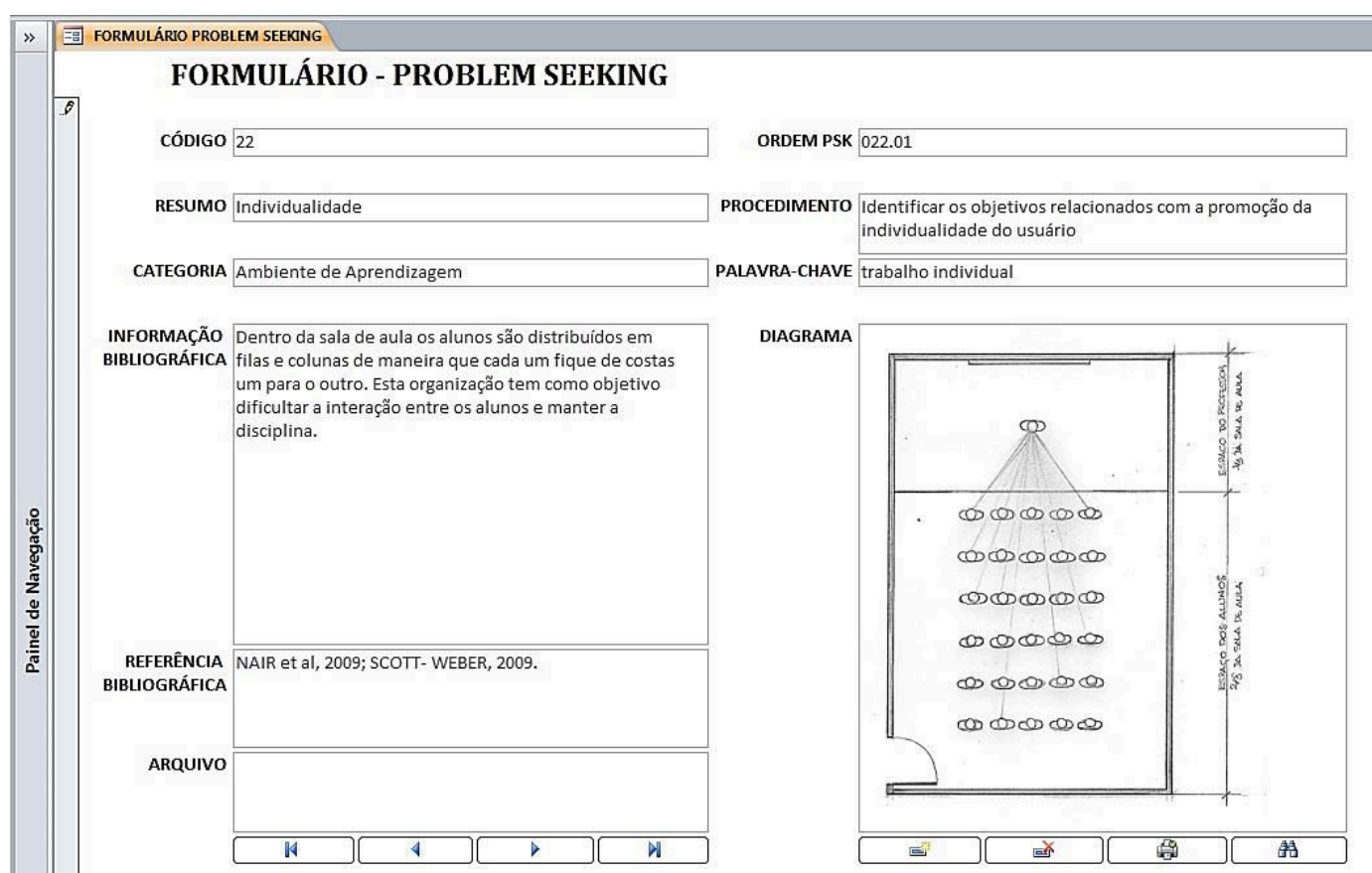

Fonte: Autor 
Figura 3 - Formulário de cadastro de dados

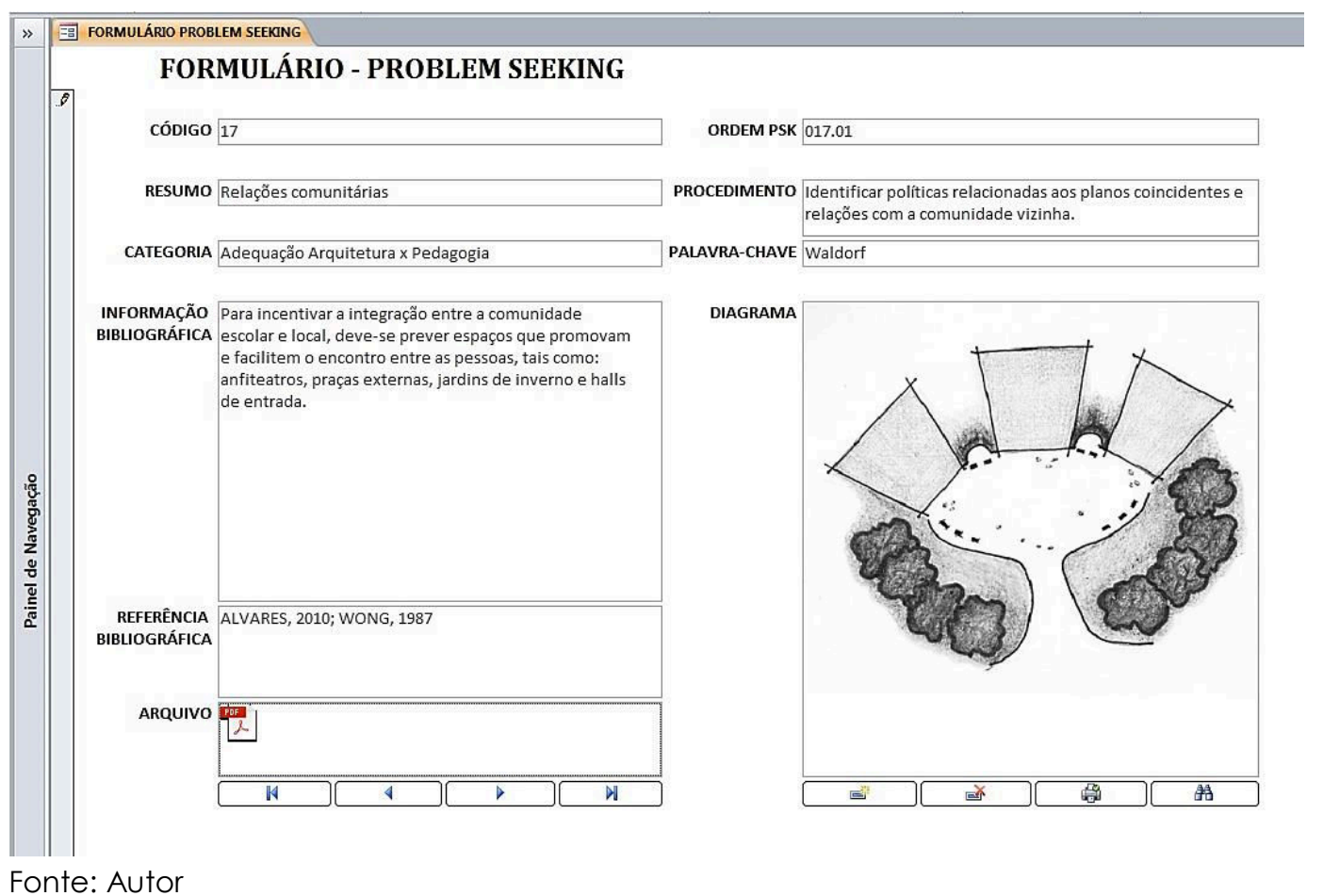

\section{CONSIDERAÇÕES FINAIS}

A escola por si só é um espaço de grande importância por abrigar o processo de ensino e aprendizagem de crianças e jovens. Proporcionar aos alunos, professores e funcionários ambientes escolares de qualidade é investir na formação dos futuros cidadãos brasileiros. Foi visando à qualidade do ambiente de aprendizagem que esta pesquisa buscou o enfoque: métodos pedagógicos e psicologia ambiental. Sabe-se que o espaço escolar é capaz de contribuir positivamente para o aprendizado dos estudantes. Mas, isso somente acontece quando um ambiente de aprendizagem dá suporte às atividades pedagógicas e estimula os alunos em seu aprendizado. A melhoria do ambiente escolar está intimamente relacionada ao processo de projeto que, por sua vez, apoia-se no Programa Arquitetônico. Este documento necessita de informações precisas, claras, organizadas e no formato adequado para o desenvolvimento do projeto. Informações científicas devem ser de fácil acesso para orientar o trabalho do projetista. Dessa forma, vislumbra-se propostas arquitetônicas com espaços de aprendizagem, funcionais e belos, bem como fundamentadas nas diretrizes das suas pedagogias e em novas informações sobre a psicologia ambiental. Somente assim o espaço escolar poderá oferecer aos alunos, professores e funcionários um clima positivo e produtivo, tornando-se o "terceiro professor".

\section{AGRADECIMENTOS}

A Fapesp pelo financiamento do projeto. 


\section{REFERÊNCIAS}

AZEVEDO, G. A. N. Arquitetura Escolar e Educação: Um Modelo Conceitual de Abordagem Interacionista. 2002. Tese (Doutorado em Engenharia de Produção) - Universidade Federal do Rio de Janeiro, Rio de Janeiro.

AZEVEDO, G. A. N. Sobre o papel da Arquitetura Escolar no cotidiano da educação: Análise das Interações Pessoa-Ambiente para a transformação qualitativa do lugar pedagógico. In: XIV Entac - Encontro Nacional de Tecnologia do Ambiente Construído. Anais... Juiz de Fora, out. 2012.

BARRETT, P., ZHANG, Y., MOFFAT, J., KOBBACY, K. A holistic, multi-level analysis identifying the impact of classroom design on pupils' learning. Building and Environment, v. 59, p. 678-689, 2013.

BRASIL. Parâmetros Curriculares Nacionais: introdução aos parâmetros curriculares nacionais. Brasília: MEC/SEF, 1997.

BUFFA, E., PINTO, G. A. Arquitetura e educação: organização do espaço e propostas pedagógicas dos grupos escolares paulistas, 1893/1971. São Carlos: EdUFSCAR/INEP, 2002.

CLEVELAND, B. W. Engaging spaces: Innovative learning environments, pedagogies and student engagement in the middle years of school. 2011. Tese. (Doutorado) - University of Melbourne, Melbourne.

CUNHA, C. da. Os muitos "Brasis" e a qualidade da Educação. In: Anuário da Educação 2013. São Paulo: Editora Moderna, 2013. p. 148.

DELIBERADOR, M. O processo de projeto da arquitetura escolar no Estado de São Paulo: caracterização e oportunidades. 2010. Dissertação (Mestrado em Engenharia Civil) - Faculdade de Engenharia Civil, Arquitetura e Urbanismo da Universidade Estadual de Campinas, Campinas.

ELALI, G. A. A área das Relações Pessoa-Ambiente e algumas de suas contribuições para a APO. In: Entac - XII Encontro Nacional de Tecnologia do Ambiente Construído. Anais... Fortaleza, 2008.

ESCOLANO, A. Arquitetura como Programa - Espaço-escola e currículo. In: FRAGO, A. V. Currículo, Espaço e Subjetividade: a Arquitetura como Programa. 2 ed. Rio de Janeiro: DP\&A, 2001.

FISHER, K. Linking Pedagogy and Space. Melbourne: Department of Education and Training, 2005.

FRANÇA, V. Capacitar escola e professores são metas possíveis. O Estado de São Paulo, p. h2, 25 abr. 2014.

GRAVATÁ, A., PIZA, C., MAYUMO, C, SHIMAHARA, E. Volta ao mundo em 13 escolas. São Paulo: Fundação Telefônica, 2013.

HORAYANGKURA, V. Incorporating Environment-Behavior Knowledge into the Design Process: An Elusive Challenge for Architects in the 21st Century. Social and Behavioral Sciences, v. 50, p. 30-41, 2012.

KOWALTOWSKI, D. C. C. K. Arquitetura escolar o projeto do ambiente de ensino. São Paulo: Oficina de Textos, 2011.

LAWSON, B. How designers think. The Design Process demystified. 4. ed. Oxford: Elsevier, 2005. 
LIPPMAN, P. C. Evidence-based design of elementary and secondary schools. Hoboken, N.J: J. Wiley, 2010.

MACHADO, E. S., SILVA, H., FLEMMING, L., CAVALCANTI, B. P., AZEVEDO, G. A. N., RHEINGANTZ, P. F. Uma reflexão sobre métodos utilizados em APO: Estudo de caso da creche Edson Luiz/RJ. In: Entac - XII Encontro Nacional de Tecnologia do Ambiente Construído. Anais... Fortaleza: 2008

MARTIN, S. H. The Classroom Environment and its effects on the practice of teachers. Journal of Environmental Psychology, v. 22, n. 1-2, p. 139-156, mar. 2002.

MOREIRA, D. C. Caracterização de um aplicativo computacional para o desenvolvimento do programa arquitetônico no ensino de projeto. Gestão e Tecnologia de projetos, p. 14-29, 2011.

NAIR, P., FIELDING, R., LACKNEY, J. The language of School Design. Design Patterns for the 21th Century School. 2 ed. EUA: National Clearinghouse for Educational Facilities, 2009.

ORNSTEIN, S. W., ONO, R. Post-Occupancy Evaluation and Design Quality in Brazil: Concepts, Approaches and an example of application. Architectural Engineering and Design Management, v. 6, 2010.

PEÑA, W. M., PARSHALL, S. A. Problem Seeking: an architectural programming primer. 4 ed. New York: John Wiley \& Sons, 2001.

SANOFF, H. School Building Assessment Methods. Washington: National Clearinghouse for Educational Facilities, 2001.

SAVIANI, D. História das ideias pedagógicas no Brasil. Campinas: Autores Associados, 2007.

SCOTT-WEBBER. In Sync. Environmental Behavior Research and the Design of Learning Spaces. Michigan: The Society for College and University Planning, 2009.

TAYLOR, A. P. Linking architecture and education: sustainable design for learning environments. Albuquerque: University of New Mexico Press, 2009. 